\title{
Identification of non-recurrent submicroscopic genome imbalances: the advantage of genome-wide microarrays over targeted approaches
}

\author{
David A Koolen ${ }^{1}$, Erik A Sistermans ${ }^{1}$, Willy Nilessen ${ }^{1}$, Samantha JL Knight ${ }^{2,3}$,
} Regina Regan ${ }^{2,3}$, Yan T Liu ${ }^{2}$, R Frank Kooy ${ }^{4}$, Liesbeth Rooms ${ }^{4}$, Corrado Romano ${ }^{5}$, Marco Fichera ${ }^{5}$, Albert Schinzel ${ }^{6}$, Alessandra Baumer ${ }^{6}$, Britt-Marie Anderlid ${ }^{7}$, Jacqueline Schoumans ${ }^{7}$, Ad Geurts van Kessel ${ }^{1}$, Magnus Nordenskjold ${ }^{7}$ and Bert BA de Vries ${ }^{*}, 1$

\footnotetext{
${ }^{1}$ Department of Human Genetics, Nijmegen Centre for Molecular Life Sciences, Radboud University Nijmegen Medical Centre, Nijmegen, The Netherlands; ${ }^{2}$ Oxford Genetics Knowledge Park, Wellcome Trust Centre for Human Genetics, Oxford, UK; ${ }^{3}$ Oxford NIHR Biomedical Research Centre, Oxford Radcliffe Hospitals NHS Trust, Churchill Hospital, Oxford, UK; ${ }^{4}$ Department of Medical Genetics, University of Antwerp, Antwerp, Belgium; ${ }^{5}$ Unit of Pediatrics and Medical Genetics, Department for Mental Retardation, IRCCS Oasi Research Institute, Troina, Italy; ${ }^{6}$ Institute of Medical Genetics, University of Zurich, Schwerzenbach, Switzerland; ${ }^{7}$ Department of Molecular Medicine and Surgery, Karolinska University Hospital, Stockholm, Sweden
}

Genome-wide analysis of DNA copy-number changes using microarray-based technologies has enabled the detection of de novo cryptic chromosome imbalances in approximately $10 \%$ of individuals with mental retardation. So far, the majority of these submicroscopic microdeletions/duplications appear to be unique, hampering clinical interpretation and genetic counselling. We hypothesised that the genomic regions involved in these de novo submicroscopic aberrations would be candidates for recurrent copy-number changes in individuals with mental retardation. To test this hypothesis, we used multiplex ligationdependent probe amplification (MLPA) to screen for copy number changes at eight genomic candidate regions in a European cohort of 710 individuals with idiopathic mental retardation. By doing so, we failed to detect additional submicroscopic rearrangements, indicating that the anomalies tested are non-

recurrent in this cohort of patients. The break points flanking the candidate regions did not contain low copy repeats and/or sequence similarities, thus providing an explanation for its non-recurrent nature. On the basis of these data, we propose that the use of genome-wide microarrays is indicated when testing for copy-number changes in individuals with idiopathic mental retardation.

European Journal of Human Genetics (2008) 16, 395-400; doi:10.1038/sj.ejhg.5201975; published online 9 January 2008

Keywords: array $\mathrm{CGH}$; mental retardation; microarray; microdeletion; microduplication; MLPA

*Correspondence: Dr BBA de Vries, Department of Human Genetics 849, Radboud University Nijmegen Medical Centre, PO Box 9101, Nijmegen $6500 \mathrm{HB}$, The Netherlands.

Tel: + 312436139 46; Fax: + 312436687 74;

E-mail: b.devries@antrg.umcn.nl

Received 11 May 2007; revised 30 October 2007; accepted 14 November 2007; published online 9 January 2008
Introduction

Genome-scanning array technologies, such as microarraybased comparative genomic hybridisation (array CGH), enable the detection of interstitial submicroscopic DNA copy-number alterations in individuals with mental retardation (MR) of unknown aetiology. De novo submicroscopic alterations have been identified in approximately $10 \%$ of individuals with MR using both bacterial artificial 
chromosome (BAC) microarrays ${ }^{1-8}$ and single-nucleotide polymorphism-based microarrays. ${ }^{9}$

Using genome-wide microarray strategies, novel recurrent interstitial submicroscopic aberrations have only been reported sparsely in individuals with $\mathrm{MR} \cdot{ }^{10-17}$ So far, the vast majority of the cryptic microdeletions/duplications identified appear to be unique, which hampers its clinical interpretation and counselling of the families. However, because these genomic imbalances are likely to harbour dosage sensitive genes related to the pathogenesis of MR, we hypothesised that the genomic regions involved in de novo submicroscopic aberrations are candidates for recurrent copy-number changes in individuals with idiopathic MR. To test this hypothesis, we subjected eight pre-selected regions to targeted copy-number analysis using multiplex ligation-dependent probe amplification (MLPA) in a cohort of 710 individuals with idiopathic MR and compared the efficacy of our targeted MLPA-based approach to genomewide scanning strategies.

\section{Materials and methods \\ Subjects}

In total, 710 mentally retarded individuals with or without facial dysmorphisms or congenital malformations were included in this study. All individuals exhibited normal G-banded karyotypes at 550-band resolution. Genomic DNA was prepared from blood lymphocytes by standard procedures. The DNA samples were derived from Nijmegen, The Netherlands $(n=200)$, Oxford, UK $(n=200)$, Schwerzenbach, Switzerland $(n=100)$, Stockholm, Sweden $(n=80)$, Antwerp, Belgium $(n=80)$, and Troina, Italy $(n=50)$.

\section{Selection of novel submicroscopic aberrations and in silico LCR analysis}

We selected eight de novo submicroscopic copy aberrations for testing among individuals with MR. The aberrations varied in size from $480 \mathrm{~kb}$ to $12.4 \mathrm{Mb}$ and were dispersed throughout the genome (Table 1). The aberrations were previously identified in a cohort of 100 mentally retarded

Table 1 Candidate regions screened for DNA copy-number changes

\begin{tabular}{llccc}
\hline & Location & Start $(\mathrm{Mb})^{\mathrm{a}}$ & End $(\mathrm{Mb})^{\mathrm{a}}$ & Size $(\mathrm{Mb})$ \\
\hline 1 & 1p34.3p34.2 & 39.2 & 43.1 & 3.85 \\
2 & 2q23.1q23.2 & 149.2 & 150.1 & 0.92 \\
3 & 3q27.1q29 & 184.3 & 196.7 & 12.42 \\
4 & 5q35.1 & 170.5 & 171.5 & 0.97 \\
5 & 9q31.1 & 99.7 & 102.6 & 2.85 \\
6 & 9q33.1 & 115.3 & 115.8 & 0.48 \\
7 & 11q14.1q14.2 & 77.8 & 85.1 & 7.28 \\
8 & 12q24.21q24.23 & 114.9 & 116.9 & 1.98 \\
\hline
\end{tabular}

${ }^{a}$ On the basis of 32k BAC microarray data (NCBI, Build 35, May 2004). ${ }^{6}$ individuals using genome-wide tiling path resolution array $\mathrm{CGH}^{1}{ }^{1}$ The $2 \mathrm{q} 23.1 \mathrm{q} 23.2$ microdeletion partly overlapped with a microdeletion previously reported by our group. ${ }^{8,18}$

The flanking $400 \mathrm{~kb}$ break point regions of the eight candidate regions were screened for the presence of homologous low copy repeats (LCRs) using the Segmental Duplication Database (http://humanparalogy.gs.washington. edu) and BLAST2 (http://www.ncbi.nlm.nih.gov/blast/bl2seq/ wblast2.cgi) analyses. The break points were defined by the average start and end positions, respectively, of the first and last flanking BAC clone that identified the genome imbalance (based on NCBI, Build 35, May 2004).

\section{Multiplex ligation-dependent probe amplification}

For the MLPA screening two to seven probes were designed within exonic sequences in the genomic regions of interest (Table 2) according to a protocol provided by MRC-Holland (http://www.mlpa.com/pages/support_desing_synthetic_ probespag.html). The same probes had also been used for the confirmation of the de novo aberrations, previously identified by genome-wide tiling resolution array $\mathrm{CGH}$ (Figure 1). ${ }^{1}$ The MLPA probes were combined in one MLPA assay in conjunction with four standard control probes in three different genes, VIPR2, MRPL41 and KIAA0056. MLPA reactions using $200 \mathrm{ng}$ genomic DNA were performed as described previously. ${ }^{19,20}$ All MLPA reagents were obtained from MRC-Holland, Amsterdam, The Netherlands. Amplification products were identified and quantified by electrophoresis on a capillary sequencer (ABI 310, ABI 3100, ABI 3130 or ABI 3730), using GeneMapper software (Applied Biosystems, Foster City, USA). For copy-number quantification data were normalised by dividing each probe's peak area by the average peak area of the control probes of the sample. The normalised peak patterns were divided by the average peak area of all the samples in the same experiment. For all DNA samples, we computed the coefficient of variation (c.v.) of the normalised signal strength over the controls. If a particular sample had a c.v. of more than 15, the result of the analysis for that particular sample was discarded. If a particular probe had a c.v. of more than 15 over all samples tested, the analysis was repeated. Copy-number change detection was based on thresholds for gains and losses of 1.30 and 0.70 , respectively. The MLPA analyses were repeated for all samples in which an aberration was identified. For these confirmation experiments, DNA samples of healthy controls were used for the normalisation. If available, DNA of positive controls were included in the MLPA assays.

\section{Results and discussion}

We used MLPA to look for copy-number changes at eight pre-selected genomic regions in a European cohort comprising 710 individuals with idiopathic MR with or without associated dysmorphisms or congenital anomalies. 
Table 2 MLPA probe information

\begin{tabular}{|c|c|c|c|c|}
\hline Gene & Band & Size & $5^{\prime}$ hybridisation sequence $e^{a}$ & $3^{\prime}$ hybridisation sequence $e^{b}$ \\
\hline KCNQ4 & 34.2 & 100 & AGGGCAACATCTTCGCCACGTCCGCGCT & GCGCAGCATGCGCTTCCTGCAGATCCTGC \\
\hline EDN2 & 4.2 & 124 & CGGGAGCСTCGGTCCACACATTCCAGGTGGAGGAAGAGAT & AGTGTCGTGAGCTGGAGGAACATTGGGAAGGAAGCCCGCGG \\
\hline ZMYND12 & 34.2 & 128 & ССАTGTTTGACССТTACCGGCCACTGTACGGGCCTITCTGGAC & TTGGACTCCTTGGGAGTCGTTTCTCGGCCATTTGACCCGTGGG \\
\hline MACF1 & 34.3 & 92 & TGGAATGTTTCACTGCTCCCAAGG & AGCGGGTAATGAGAGTGGCACTTAG \\
\hline MBD5 & $2 q 23.1$ & 84 & CAAAGAGTGTGACGGAGGGGA & CAAGGAAGGAGGTCTTCCAGC \\
\hline$E P C 2$ & 23.1 & 92 & GAGGTGGAAGGTGAAGTATTTGTTT & TCACCTGGTIITTGTTTGCTATCTG \\
\hline MBD5 & 23.1 & 100 & AACAGAAGGTTTGGAAGCCTACAGC & CGTGTCCGGAAAAGGAACAGAAAGTAAGC \\
\hline$E P C 2$ & $2 \mathrm{q} 23.1$ & 108 & CAGTTAGTTCAGATGCAAAGGCAGCAACTTGCC & CAGCTTCAGCAGAAACAGCAATCTCAGCATTCC \\
\hline KIF5C & $2 \mathrm{q} 23.1$ & 112 & CСGTGTTTGTATTTCGCCCACTAGGGGAAGCTC & ATGACCCCCAGCTCATGGGGATCATCCCACGAATT \\
\hline MBD5 & $2 \mathrm{q} 23.1$ & 120 & CGGGGATTTGGAGAGCTGCTA & CAAGACCTGGTCCTAGAGGAGCAGTC \\
\hline MBD5 & $2 q 23.1$ & 124 & CTAAATACСССАAGCAGTGCAGCTTTTССТАСТGСАТСТGC & CGGAAGTAGTTCTGTAAAGAGTCAGCCTGGTTTGCTGGGAA \\
\hline MAP3K13 & $3 q 27.2$ & 84 & GCACGATGGCCAACTITCAGG & AGCACCTGAGCTGCTCСТСTT \\
\hline & $3 q 28$ & 88 & AGATTGACTCCTTGAC & CAGCATCTTGGCTGACCTTGAGT \\
\hline TP723L & $3 q 28$ & 92 & GGAGAATGGGGTGATATTGGAGAAG & СTGCATGATAAGACСTGTGACСТTC \\
\hline HRASLS & $3 q 29$ & 100 & ССТTTACAAGCGCCAAGTCTGTATTCAGC & AGTAAGGCCCTGGTGAAAATGCAGCTCTT \\
\hline FGF18 & $5 q 35.1$ & 108 & ССАТСТ & TCCCGCAGGTGTTTACACTTCСTGCTGCTGTGC \\
\hline STK10 & $5 q 35.1$ & 112 & СТСGСССТGTGССАССССААСТGTGССТGATAGAC & CTGCCСCAGCGTTCCTGACTTCTTGCTGGCCTGTG \\
\hline$D C-U b P$ & $5 q 35.1$ & 120 & CTTGGCACCGCCAATCAACATGATAGAGG & CATAGAGACTCTGGATATTCСТGAGCСАCСACCC \\
\hline STX17 & 31.1 & 92 & CAGGTGCACTCATCGGGGGAATGGT & AGGGGGTCCTATTGGCCTCCTTGCA \\
\hline PRG-3 & $9 q 31.1$ & 104 & CGAATGCACTGACACTTTTCAGGTGCATATC & САAGGATTCTTCTGTCAGGACGGAGACTTAA \\
\hline GRIN3A & $9 q 31.1$ & 108 & GCCACAGCCACCATC & СТСАТTСССАGСАСGATGAАСTGCATGGAGGTG \\
\hline C9orf27 & 33.1 & 92 & CAAAGGCTCTGTGTTAGTGGATTCA & CAAGCAACCTGTACTCCTCAAAGAA \\
\hline C9orf27 & $9 q 33.1$ & 100 & GTATGCAGACTCATCCATCCATGAATCTA & GATTGCAGGGATGTGACCTATGTAATGAA \\
\hline$G A B 2$ & $11 q 14.1$ & 84 & СТССAGCCAGCCAACTCTGTT & CACGTTTGAACCСССТGTGTC \\
\hline DLG2 & $11 \mathrm{q} 14.1$ & 112 & CTGACGGGCTTTCTGCCCAAGAG & ССТССТСАССССАGСАGATGTCСAGAGCTGATTT \\
\hline PICAM & $11 \mathrm{q} 14.2$ & 120 & CACAGTGTCACCGGCTCTGCCGTATCCAAGACAGTATGC & AAGGCCACGACC CACGAGATCATGGGGCCCAAGAAAAAG \\
\hline NOS1 & $12 \mathrm{q} 24.22$ & 112 & CACATGTTCGGTGTTCAGCAAATCCAGCCCAATGT & CATTTCTGTTCGTCTCTTCAAGCGCAAAGTTGGGG \\
\hline KSR2 & $12 \mathrm{q} 24.23$ & 120 & СTGGCTTTCTCATGGCTTACССАTTGTCTCTGCTCTTCT & GTTCCAACTCAGGAGGCAACCTITCCAAACAAGACTGGA \\
\hline
\end{tabular}

${ }^{\text {a The }} 5^{\prime}$ half-probe is preceded by the $5^{\prime}$ universal primer tag.

${ }^{\text {b}}$ The $3^{\prime}$ half-probe is preceded by a $5^{\prime}$ phosphate group and followed by the $3^{\prime}$ universal primer tag. 

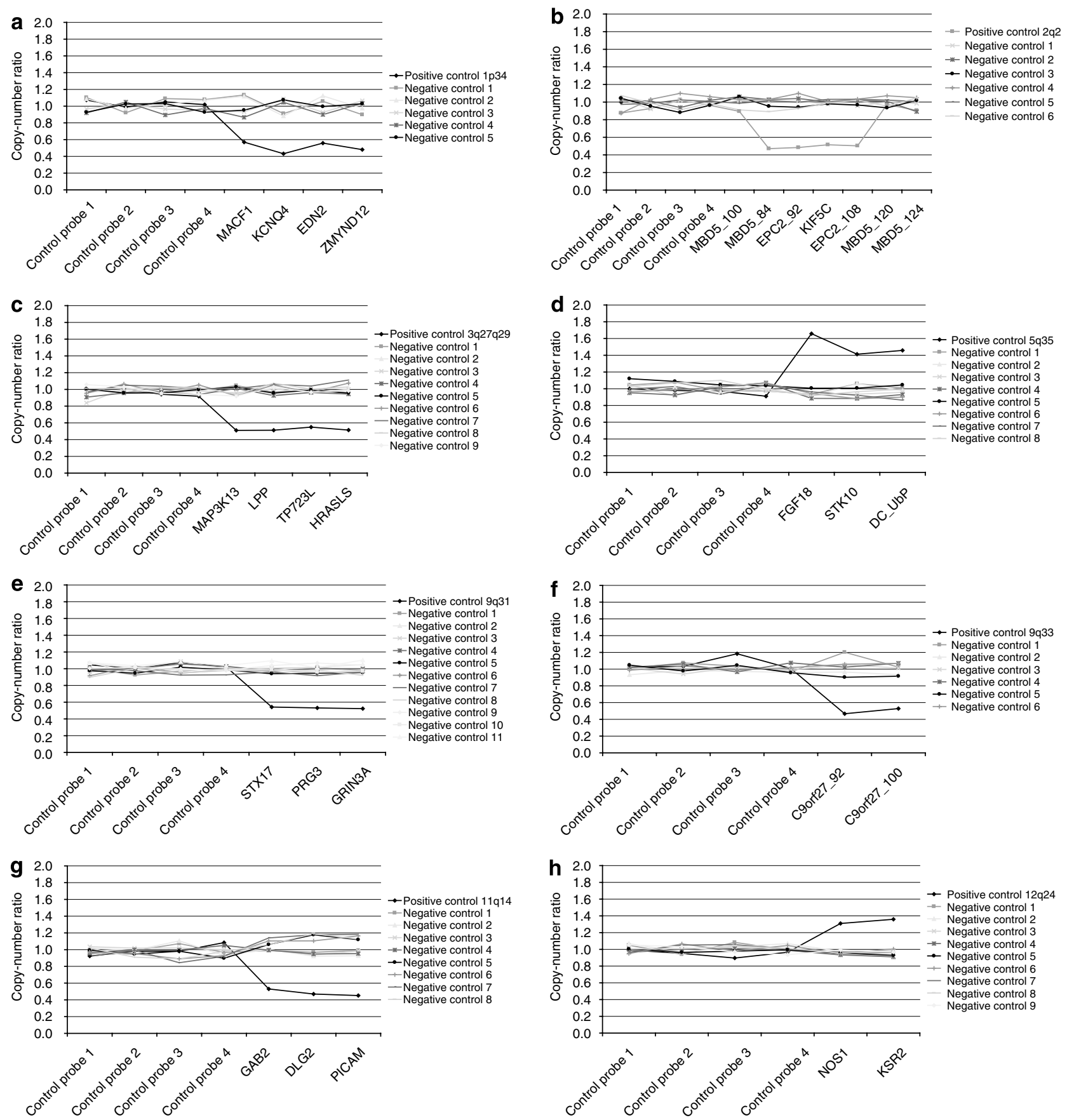

Figure 1 MLPA validation of submicroscopic genome imbalances. (a) Loss 1p34.3p34.2, (b) loss 2q23.1q23.2, (c) loss 3q27q29, (d) gain 5q35, (e) loss 9q31.1, (f) loss 9q33.1, (g) loss 11q14.1q14.2, (h) gain 12q24.21q24.23.

Causative copy-number changes in these eight regions were previously described in single individuals with MR. ${ }^{1}$ The eight regions were based upon the unique and de novo aberrations that had been found in our initial study among a cohort of $100 \mathrm{MR}$ patients using genome-wide tiling path resolution array $\mathrm{CGH}^{1}{ }^{1}$ Through the MLPA assay, we failed to detect additional submicroscopic rearrangements at all candidate regions in this patient cohort. Figure 2 shows an example of the data obtained by the MLPA copy-number screening of the candidate regions. The loss of the 11q14.1 segment is clearly demonstrated in the positive control sample, whereas in the remaining test samples in the assay, 


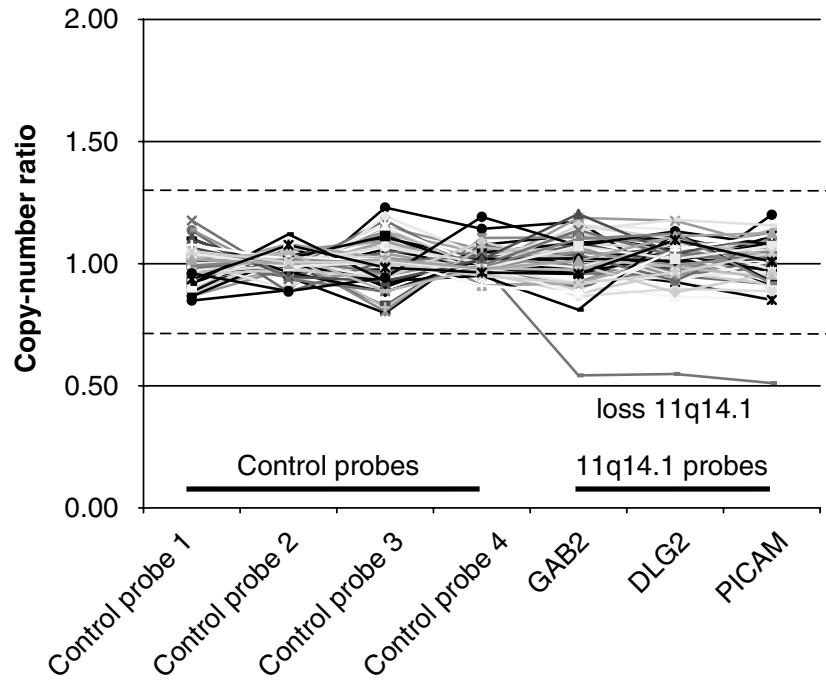

Figure 2 Copy-number screening at $11 \mathrm{q} 14.1$ using multiplex ligation-dependent probe amplification. $x$-axis, standard control probes and three probes hybridising to $11 \mathrm{q} 14.1$ (for a complete list of probe sequences, see Table 2). $y$-axis, normalised copy-number ratios. Copy-number change detection is based on thresholds for gains and losses of 1.30 and 0.70 , respectively. The loss of the $11 \mathrm{q} 14.1$ segment is clearly demonstrated in the positive control sample, whereas in the remaining test samples in the same assay, no copynumber changes could be identified.

no copy-number changes are found. Subsequently, we screened the flanking break point regions of the preselected candidate regions for the presence of LCRs and/or sequence similarities that might predispose for the occurrence of non-allelic homologous recombination events leading to loss or gain of the intervening DNA sequence. ${ }^{21}$ However, no significant LCRs and/or sequence similarities could be identified. The present study is the first report of a comprehensive screen for interstitial submicroscopic aberrations in a large cohort of individuals with MR using MLPA. Of course, the results might have been different if other regions, such as subtelomeric regions, had been analysed in this cohort. Although copy-number changes in these latter regions are usually not mediated by LCRs, which is similar to our eight selected regions, they are in regions that have already been associated with recurrent aberrations.

Others have employed a variety of microarray-based targeted approaches to detect recurrent submicroscopic aberrations. Sharp et $a l^{15}$ for example, generated a segmental duplication BAC microarray targeted to 130 potential rearrangement hot spots in the human genome. By using this targeted approach, they tested 290 individuals with MR and identified 16 pathogenic rearrangements, including four microdeletions in $17 \mathrm{q} 21.31 .^{22}$ The phenotypic similarities between the individuals with an overlapping 17q21.31 deletion subsequently pointed to a new microdeletion syndrome. ${ }^{10,17,22}$ More recently, several other novel recurrent microdeletions that are mediated by flanking LCRs have been identified. These recurrent aberrations may give rise to new genomic disorders, such as the $15 \mathrm{q} 24$ microdeletion syndrome ${ }^{16}$ and the $10 \mathrm{q} 22 \mathrm{q} 23$ microdeletion syndrome. ${ }^{23}$ Targeted microarrays have been developed with target sequences corresponding to genomic regions of known clinical significance, such as the chromosome subtelomeres and regions implicated in well-known human genomic disorders. ${ }^{24-27}$ Using these targeted microarrays, Shaffer et $a l^{28}$ found clinically relevant genomic alterations in $5.6 \%$ of 1500 consecutive cases referred to the clinic for a variety of developmental problems. Indeed, these targeted microarrays have some advantages over genome-wide microarray scanning technologies, especially in a diagnostic setting, as parental samples are not requisite for the clinical interpretation of the array CGH findings. ${ }^{29}$ In addition, in most cases there is ample information available about the clinical consequences of these submicroscopic copy-number alterations, thus facilitating the genetic counselling of families. However, most known microdeletion syndromes, will be clinically recognised by experienced clinical geneticists and can be confirmed by specifically designed FISH tests. Therefore, patients with a recognisable microdeletion syndrome will only rarely be sent in for microarray analysis. Moreover, in contrast to genome-wide microarray approaches, targeted approaches will miss sporadic DNA copy-number changes in MR, as these regions will not be represented on such microarrays. ${ }^{30}$ The latter might be overcome if the targeted array is up-dated, regularly, by including all newly and uniquely reported microaberrations. By doing so, one might eventually end up with a whole genome-wide array.

Our study indicates that de novo submicroscopic aberrations that are not flanked by genomic architectural features conferring susceptibility to rearrangements appear to be non-recurrent in a large cohort of patients. In the future it is conceivable that advanced technologies and results from large numbers of patient studies will help unravel the majority of genes involved in MR, thereby making targeted testing approaches more viable. However, in the meantime, we recommend the use of genome-wide microarrays when testing idiopathic MR patients for genome imbalance.

\footnotetext{
Acknowledgements

This study was supported by grants from the European commission under FP6, AnEUploidy project (BBAdV and DAK, LSHG-CT-2006037627) the Netherlands Organisation for Health Research and Development (BBAdV, ZonMW 907-00-058; DAK, ZonMW 920-03338; HGB and JAV, ZonMW 912-04-047), Hersenstichting Nederland (BBAdV), The Oxford Genetics Knowledge Park (University of Oxford) (SILK, YTL and RR) and The Oxford NIHR Biomedical Research Centre (Oxford Radcliffe Hospitals NHS Trust) (SJLK and RR) and The Swedish Research Council (JS and BMA).
} 


\section{References}

1 de Vries BB, Pfundt R, Leisink M et al: Diagnostic genome profiling in mental retardation. Am J Hum Genet 2005; 77: 606-616.

2 Engels H, Brockschmidt A, Hoischen A et al: DNA microarray analysis identifies candidate regions and genes in unexplained mental retardation. Neurology 2007; 68: 743-750.

3 Krepischi-Santos AC, Vianna-Morgante AM, Jehee FS et al: Wholegenome array-CGH screening in undiagnosed syndromic patients: old syndromes revisited and new alterations. Cytogenet Genome Res 2006; 115: 254-261.

4 Menten B, Maas N, Thienpont B et al: Emerging patterns of cryptic chromosomal imbalance in patients with idiopathic mental retardation and multiple congenital anomalies: a new series of 140 patients and review of published reports. J Med Genet 2006; 43: 625-633.

5 Rosenberg C, Knijnenburg J, Bakker E et al: Array-CGH detection of micro rearrangements in mentally retarded individuals: clinical significance of imbalances present both in affected children and normal parents. J Med Genet 2006; 43: 180-186.

6 Schoumans J, Ruivenkamp C, Holmberg E, Kyllerman M, Anderlid BM, Nordenskjold M: Detection of chromosomal imbalances in children with idiopathic mental retardation by array based comparative genomic hybridisation (array-CGH). J Med Genet 2005; 42: 699-705.

7 Shaw-Smith C, Redon R, Rickman L et al: Microarray based comparative genomic hybridisation (array-CGH) detects submicroscopic chromosomal deletions and duplications in patients with learning disability/mental retardation and dysmorphic features. J Med Genet 2004; 41: 241-248.

8 Vissers LE, de Vries BB, Osoegawa K et al: Array-based comparative genomic hybridization for the genomewide detection of submicroscopic chromosomal abnormalities. Am J Hum Genet 2003; 73: $1261-1270$.

9 Friedman JM, Baross A, Delaney $\mathrm{AD}$ et al: Oligonucleotide microarray analysis of genomic imbalance in children with mental retardation. Am J Hum Genet 2006; 79: 500-513.

10 Koolen DA, Vissers LE, Pfundt R et al: A new chromosome 17q21.31 microdeletion syndrome associated with a common inversion polymorphism. Nat Genet 2006; 38: 999-1001.

11 Menten B, Buysse K, Zahir F et al: Osteopoikilosis, short stature and mental retardation as key features of a new microdeletion syndrome on 12q14. J Med Genet 2007; 44: 264-268.

12 Rajcan-Separovic E, Harvard C, Liu X et al: Clinical and molecular cytogenetic characterisation of a newly recognised microdeletion syndrome involving 2p15-16.1. J Med Genet 2007; 44: $269-276$.

13 Redon R, Ishikawa S, Fitch KR et al: Global variation in copy number in the human genome. Nature 2006; 444: 444-454.

14 Redon R, Baujat G, Sanlaville D et al: Interstitial 9q22.3 microdeletion: clinical and molecular characterisation of a newly recognised overgrowth syndrome. Eur J Hum Genet 2006; 14: $759-767$
15 Sharp AJ, Locke DP, McGrath SD et al: Segmental duplications and copy-number variation in the human genome. Am J Hum Genet 2005; 77: 78-88.

16 Sharp AJ, Selzer RR, Veltman JA et al: Characterization of a recurrent 15q24 microdeletion syndrome. Hum Mol Genet 2007; 16: $567-572$.

17 Shaw-Smith C, Pittman AM, Willatt L et al: Microdeletion encompassing MAPT at chromosome $17 \mathrm{q} 21.3$ is associated with developmental delay and learning disability. Nat Genet 2006; 38: $1032-1037$.

18 Koolen DA, Vissers LE, Nillesen W et al: A novel microdeletion, $\operatorname{del}(2)(\mathrm{q} 22.3 \mathrm{q} 23.3)$ in a mentally retarded patient, detected by array-based comparative genomic hybridization. Clin Genet 2004; 65: $429-432$

19 Koolen DA, Nillesen WM, Versteeg MH et al: Screening for subtelomeric rearrangements in 210 patients with unexplained mental retardation using multiplex ligation dependent probe amplification (MLPA). J Med Genet 2004; 41: 892-899.

20 Schouten JP, McElgunn CJ, Waaijer R, Zwijnenburg D, Diepvens F, Pals G: Relative quantification of 40 nucleic acid sequences by multiplex ligation-dependent probe amplification. Nucleic Acids Res 2002; 30: e57.

21 Stankiewicz P, Lupski JR: Molecular-evolutionary mechanisms for genomic disorders. Curr Opin Genet Dev 2002; 12: 312-319.

22 Sharp AJ, Hansen S, Selzer RR et al: Discovery of previously unidentified genomic disorders from the duplication architecture of the human genome. Nat Genet 2006; 38: 1038-1042.

23 Balciuniene J, Feng N, Iyadurai K et al: Recurrent 10q22-q23 deletions: a genomic disorder on $10 \mathrm{q}$ associated with cognitive and behavioral abnormalities. Am J Hum Genet 2007; 80: 938-947.

24 Bejjani BA, Saleki R, Ballif BC et al: Use of targeted array-based CGH for the clinical diagnosis of chromosomal imbalance: is less more? Am J Med Genet A 2005; 134: 259-267.

25 Cheung SW, Shaw CA, Yu W et al: Development and validation of a CGH microarray for clinical cytogenetic diagnosis. Genet Med 2005; 7: 422-432.

26 Schaeffer AJ, Chung J, Heretis K, Wong A, Ledbetter DH, Lese MC: Comparative genomic hybridization-array analysis enhances the detection of aneuploidies and submicroscopic imbalances in spontaneous miscarriages. Am J Hum Genet 2004; 74: 1168-1174.

27 Wong A, Lese MC, Heretis $\mathrm{K}$ et al: Detection and calibration of microdeletions and microduplications by array-based comparative genomic hybridization and its applicability to clinical genetic testing. Genet Med 2005; 7: 264-271.

28 Shaffer LG, Kashork CD, Saleki R et al: Targeted genomic microarray analysis for identification of chromosome abnormalities in 1500 consecutive clinical cases. J Pediatr 2006; 149: 98-102.

29 Bejjani BA, Shaffer LG: Application of array-based comparative genomic hybridization to clinical diagnostics. J Mol Diagn 2006; 8: $528-533$.

30 Veltman JA, de Vries BBA: Diagnostic genome profiling: unbiased whole genome or targeted analysis? J Mol Diagn 2006; 8: 534-537. 